\title{
Heading which way? Y-maze chemical assays: not all crustaceans are alike
}

\author{
Matthes Kenning $^{1} \cdot$ Philipp Lehmann $^{2,3} \cdot$ Magnus Lindström $^{4} \cdot$ Steffen Harzsch $^{1}$
}

Received: 21 January 2015/Revised: 23 April 2015/ Accepted: 29 April 2015/Published online: 21 May 2015

(C) Springer-Verlag Berlin Heidelberg and AWI 2015

\begin{abstract}
In a world full of chemicals, many crustaceans rely on elaborate olfactory systems to guide behaviors related to finding food or to assess the presence of conspecifics and predators. We analyzed the responses of the isopod Saduria entomon to a range of stimuli by which the animal is likely to encounter in its natural habitat using a Y-maze bioassay. In order to document the efficiency of the experimental design, the same bioassay was used to test the behavior of the crayfish Procambarus fallax whose ability to track odors is well documented. The crayfish performed well in the Y-maze and were able to locate the source of a food-related odor with high fidelity. The isopod S. entomon reacted indifferently or with aversion to most of the stimuli applied. In 1800 trials, only four out of 15 different stimuli yielded statistically significant results, and only one odorant was found to be significantly attractive.
\end{abstract}

Communicated by H.-D. Franke.

Electronic supplementary material The online version of this article (doi:10.1007/s10152-015-0435-6) contains supplementary material, which is available to authorized users.

Matthes Kenning

matthes.kenning@googlemail.com

1 Department of Cytology and Evolutionary Biology, Zoological Institute and Museum, Ernst-Moritz-ArndtUniversity, Greifswald, Soldmannstraße 23, 17487 Greifswald, Germany

2 Department of Biological and Environmental Science, Centre of Excellence in Biological Interactions Research, University of Jyväskylä, Jyväskylä, Finland

3 Department of Zoology, Stockholm University, 10691 Stockholm, Sweden

4 Ecophysiological Laboratory, Tvärminne Zoological Station, University of Helsinki, 10900 Hanko, Finland
The findings raise several questions whether the stimuli presented and/or the experimental setup used represents an ecologically relevant situation for S. entomon. In each instance, our experiments illustrate that established methods cannot be readily transferred from one species to another.

Keywords Isopoda - Saduria entomon - Decapoda . Crayfish · Olfaction · Behavior · Flow channel

\section{Introduction}

The ability to obtain information about the environment is the fundamental basis for an organism's ecological interactions. In aquatic organisms, chemical stimuli provide highly important cues for survival and reproduction because they indicate the availability of resources such as food, shelters or substrates for larval settlement, and allow assessing the presence of predators, conspecifics and potential mates (Derby and Sorensen 2008; Thiel 2011; Wyatt 2011; Breithaupt 2011; Weissburg 2011). Aquatic crustaceans live in a world full of chemicals. Therefore, major tasks for chemosensory systems are detecting and discriminating mixtures of odors against highly variable backgrounds. The relationship of odor-guided behaviors, orientation strategies, plume structure and dispersal, and morphological aspects of the olfactory system has been intensely analyzed in a variety of generalist decapod crustaceans such as brachyuran crabs (e.g., Weissburg and Zimmer-Faust 1994), crayfish (Moore and Grills 1999), spiny lobsters (Horner 2004) and peracarid crustaceans (Premke et al. 2003; Krång and Baden 2004; Ide et al. 2006). These studies picture a highly complex dependence of flow physics, odor reception, stimulus processing and locomotory responses. Abiotic factors such as the 
properties of chemicals, water flow and plume structure, but also biotic factors such as animal size, sensor span (i.e., distance between two antennae) and the underlying neuronal circuitry of the peripheral and central olfactory pathways are only a few of the key parameters shaping olfactory-guided behaviors. Most Malacostraca studied so far are well adapted to master the challenges of olfaction. The unimodal olfactory sensilla on the first pair of antennae called aesthetascs and bimodal chemo- and mechanosensory sensilla, as well as associated brain centers are of particular importance for long-distance chemoreception (Hallberg and Skog 2011). As our present knowledge of olfactory-guided behaviors is primarily founded on studies in Decapoda, we are only beginning to explore chemoreceptive foraging in other crustacean species (e.g., Premke et al. 2003; Ide et al. 2006; Tiselius et al. 2013). This study sets out to expand our knowledge in this field beyond the classical crustacean model organisms. We analyzed the ability of the omnivorous isopod Saduria entomon (Valvifera) to localize a broad range of waterborne stimuli using a custom made Y-maze bioassay. In previous studies, it was shown that $S$. entomon possesses both the sensory (Pynnönen 1985) and central nervous equipment (Kenning and Harzsch 2013) required for receiving and processing olfactory stimuli. In order to document the efficiency of our setup, we used the same bioassay to examine olfactoryguided behavior in the marbled crayfish Procambarus fallax forma virginalis (Decapoda). It is well documented that crayfish use chemical senses to detect the presence of predators, assess social hierarchies and find shelters and food (see Breithaupt 2011). They also display a highly effective odor-tracking behavior in Y-mazes (Schneider et al. 1999).

\section{Materials and methods}

\section{Animals}

Stocks of Saduria entomon Linnaeus 1758 were collected in May 2013 with a dredge at the bottom of the Tvärminne Storfjärd, Gulf of Finland $\left(\sim 50 \mathrm{~m}, 59^{\circ} 50^{\prime} \mathrm{N}, 23^{\circ} 15^{\prime} \mathrm{E}\right)$. Animals of different sizes and both sexes were kept food deprived and without light in several aquaria with a constant supply of filtered seawater $(\sim 6 \mathrm{PSU})$ at $6{ }^{\circ} \mathrm{C}$ for $2^{1 / 2}$ weeks prior to testing. To minimize cannibalism within the stock, animals were broadly grouped into four size classes (very large, $\geq \sim 5 \mathrm{~cm}$; large, $3-5 \mathrm{~cm}$; small, 1-3 cm; very small, $\leq \sim 1 \mathrm{~cm}$ ) and kept separately. Specimens of Procambarus fallax, HAGEN 1870 forma virginalis (Martin et al. 2010)-hereafter only called $P$. fallax - originated from a colony in the Department of Cytology and Evolutionary Biology in Greifswald.
Fig. 1 Experimental setup and overview of experiments. a, b Blueprints of the Y-maze seen from different perspectives. Inflow nozzle from peristaltic pump not shown. $\mathbf{c}$ Calibrating the water flow using methylene red and standard pen ink. Note that the nets were removed prior to experiments. d Night vision shot of stimulus treatment experiment. Only three of four setups are shown. e Overview of control and odor treatment experiments. Note that the combined relative choice frequency and standard deviation from all four parallels are shown. There are no significant differences between the two branches of the Y-maze in the negative-control experiments for both, Saduria entomon and Procambarus fallax. P. fallax showed a highly significant preference for the odor. Only four experiments with $S$. entomon yielded a significant response. The combined stimulus (IV), herring $\left(\mathrm{VI}_{\mathrm{a}+\mathrm{b}}\right)$ and the amino acid taurine (XIII) had a significantly repellent effect, and only in one experiment (XIV, threonine) the stimulus was attractive (see text for details). Random chance $(50 \%$, based on the area of branches vs. total area of the maze) is indicated by the gray solid line. Asterisks denote significance levels $(* p<0.05 ; * * p<0.01 ; * * *<0.001)$

Animals of different sizes were kept food deprived for 1 week in aquaria filled with fresh water at $18^{\circ} \mathrm{C}$ before being tested (Seitz et al. 2005).

\section{Bioassay}

Laboratory experiments on S. entomon were conducted at the Tvärminne Zoological Station, Finland, using four identical replicate Y-maze setups made of PVC (Fig. 1ad). These bioassays were composed of an inflow/mixing compartment followed by a flow rectifier, a choice compartment partly separated by a partitioning wall forming the branches, the start/acclimatization compartment and an outflow section (Fig. 1a, b). A gravity-fed water flow system provided a continuous supply of filtered but otherwise untreated habitat water of about $800 \mathrm{ml} \mathrm{min}^{-1}$, yielding a quasi-laminar flow with a speed of ca. $1 \mathrm{~cm} \mathrm{~s}^{-1}$ at the downstream end without formation of visible turbulences. Retention time of the water was calculated at 20 min. All experiments were performed in a climate chamber at $6{ }^{\circ} \mathrm{C}$ in darkness, observed using night vision goggles and recorded using an infrared spotlight and camera (Sony DCR-HC47; Fig. 1d). Although the experiments were designed to focus on olfactory-mediated behaviors by excluding optical stimuli, four experiments were conducted a second time with artificial light (Philips Softone $12 \mathrm{~W}$ Energy Saver, $\sim 1.0 \mathrm{~m}$ above Y-maze, intensity: $1 \mu \mathrm{E} \mathrm{m}^{-2} \mathrm{~s}^{-1}$ at the level of the animal). Per trial and assay, a single animal was left to acclimatize at the downstream end of the channel for 5-10 min while partly exposed to the stimulus before being released (compare flow visualization in Fig. 1c). A total of 1800 trials using 14 different stimuli that this animal is likely to encounter in its natural habitat were performed (see next section and supplementary material I). A valid choice was recorded when the animal passed half of the partitioning wall. Based 

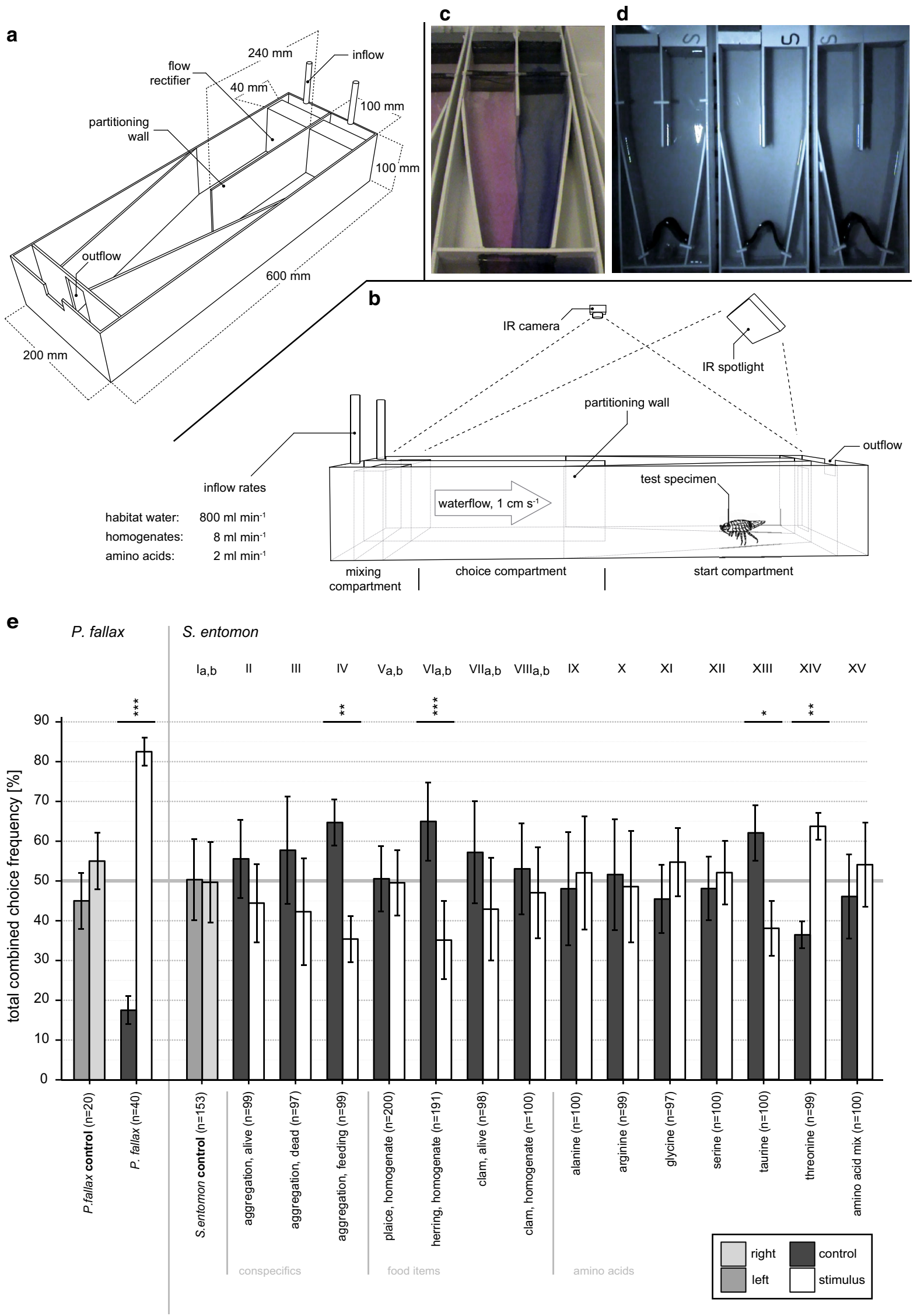
on observations in a pilot study, the maximum duration of a single trial was set to $5 \mathrm{~min}$. If by then no choice was made, the trial was stopped, counted as invalid and excluded from the analysis (see supplementary material I, note the high ratio of valid choices). Test individuals were used only once per treatment, and in all experiments except for experiment II (see below), all size classes were considered. Experiments on P. fallax were performed at the Department of Cytology and Evolutionary Biology, Greifswald, using the same Y-maze assay and flow parameters. A total of 60 trials were conducted at natural daylight to test the responses to aqueous extracts of an artificial food item.

\section{Stimuli}

We performed 15 experiments with S. entomon in four (in experiments VII and VIII two) replicate Y-maze aquaria simultaneously. Per trial, a single stimulus was applied randomly to the left or right side of the mixing compartment, while the other branch remained empty (control, application of seawater without stimulus). For the application of homogenates, we used a peristaltic pump at a flow rate of $\sim 8 \mathrm{ml} \mathrm{min}^{-1}$ and amino acid solutions were applied at $2 \mathrm{ml} \mathrm{min}^{-1}$.

\section{Negative control}

No chemical stimuli were applied. In experiments $I_{a, b}$, a total of 160 control trials were conducted at both light conditions to account for a possible left- and right-side bias. Equally, 20 control trials were performed on $P$. fallax at both light conditions.

\section{Conspecifics}

During winter, younger cohorts of $S$. entomon migrate into shallower waters (Nikitina and Spasskii 1963). The reason for this migration is unknown, but as they are effectively avoiding aggregations of larger specimens, it may be linked to reducing cannibalism in a time of scarce resources. In experiment II, we tested the response of small and very small specimens when encountering larger conspecifics. Thus, large and very large animals $(n=6)$ were caged in the mixing compartment and concealed by the flow rectifier but otherwise were left untreated.

Experiment III was designed to mimic the "smell of death" as a repellent stimulus (Kats and Dill 1998; Hazlett 2011). We tested for the reaction when confronted with aggregations of recently deceased animals placed in the mixing section ( $n=8$, dissected less than 30 min prior to experiment). To facilitate the release of metabolites, carcasses were crushed. Yet, as S. entomon also preys on conspecifics (Leonardsson 1991), this stimulus may also have an attractive quality.

In experiment IV, we tested a combined stimulus of aggregated animals and a potential food item. Fresh filets containing muscle and skin tissue of European plaice (Pleuronectes platessa) was offered to a group of $S$. entomon $(n=6)$ also caged in the mixing section (compare experiment II). The caged animals immediately started feeding on the dead fish violently, confirming our assumption that they were sufficiently deprived and motivated to locate food-related odors.

\section{Food items}

In experiments $\mathrm{V}_{\mathrm{a}, \mathrm{b}}$ and $\mathrm{VI}_{\mathrm{a}, \mathrm{b}}$, pieces of plaice muscle tissue and herring (Clupea harengus), respectively, were homogenized, filtered and applied with a peristaltic pump. Experiments were conducted at both light conditions.

Baltic clam (Macoma balthica) which is known to be a major dietary component of $S$. entomon (Ejdung and Elmgren 2001), was used in four experiments, alive and as a fluid homogenate at both light conditions $\left(\mathrm{VII}_{\mathrm{a}, \mathrm{b}}\right.$ and VIII $_{a, b}$ ).

\section{Amino acids}

In experiments IX-XV, we tested the response to the amino acids alanine, arginine, glycine, serine, taurine and threonine (Ide et al. 2006). Based on the background concentration of amino acids of ca. $2 \times 10^{-7} \mathrm{~mol} \mathrm{l}^{-1}$ in the Baltic Sea (see Mopper and Dawson 1986 and references therein), aqueous solutions were applied separately and as a mixture at an in-flow concentration of $1 \times 10^{-5} \mathrm{~mol}^{-1}$ using a peristaltic pump.

Stimulus for P. fallax

An aqueous extract of TetraWafer-Mix, a staple food mix for carnivorous and herbivorous bottom-feeding fish and crustaceans which has proven to be quite attractive for $P$. fallax, was used to test chemotaxis in the Y-maze bioassay.

\section{Statistical analysis}

Choices from all trials per replicate and experiment were combined to a choice frequency per replicate and experiment, and subsequently pooled, yielding a combined choice frequency for each experiment (absolute counts; see supplementary material II). These data were evaluated for differences in stimulus versus control treatment using Chisquared goodness-of-fit test $\left(\chi^{2}\right)$ in $\mathrm{R}$ (see supplementary material III, version 3.1.1, Team et al. 2005). We tested for a left-right bias in the control experiments, for differences 
between stimulus and control branches in the odor treatment experiments, and-where conducted-for differences in light treatments.

\section{Results}

\section{Negative control}

Figure 1e summarizes all results for the negative-control and stimulus treatment experiments. Out of 160 negativecontrol trails carried out with $S$. entomon, 153 valid trials showed that there was no preference for one branch given the lack of significance (experiment $\mathrm{I}_{\mathrm{a}+\mathrm{b}}: \chi^{2}=0.065$, $P=0.936, n=153$ ). Likewise, no statistically significant preference for one branch was found in the experiments with $P$. fallax $\left(\chi^{2}=0.2, P=0.65, n=20\right)$.

\section{Odor treatments}

When testing $P$. fallax, $82.5 \%$ of the animals were attracted to the stimulus $\left(\chi^{2}=16.9, P=3.94 \times 10^{-5}\right.$, $n=40)$. We take this as evidence that in principle the design of our bioassay is suited to analyze odor preferences in malacostracan crustaceans.

\section{Conspecifics}

No significant response from $S$. entomon was observed when confronted with aggregations of living conspecifics (experiment II). A similar reaction is seen in the "smell of death" experiment (III, conspecifics dead). Although the difference between stimulus and control branch seems more distinct, Chi-squared test yielded no significance. In the combined stimulus experiment (IV) in which conspecifics fed on plaice, a highly significant response toward the control was provoked ( $\left.\chi^{2}=8.49, P=0.004, n=99\right)$. Interestingly, neither the aggregation of animals (II) nor the fish itself $\left(\mathrm{V}_{\mathrm{a}+\mathrm{b}}\right.$, see next section) caused a comparable response.

\section{Food items}

Muscle tissue homogenate from plaice (experiment $\mathrm{V}_{\mathrm{a}+\mathrm{b}}$ ) was the least effective treatment, showing a random distribution of choices. The strongest response of all experiments with $S$. entomon was observed when exposed to a homogenate of herring muscle tissue (experiment $\mathrm{VI}_{\mathrm{a}+\mathrm{b}}$ ). Again, the animals significantly chose the control $\left(\chi^{2}=17.01, P=3.7 \times 10^{-5}, n=191\right)$. Saduria entomon showed a barely distinct response toward the control branch when encountering exudates from living clam as well as homogenates of this clam (experiments $\mathrm{VII}_{\mathrm{a}+\mathrm{b}}$ and
VIII $_{\mathrm{a}+\mathrm{b}}$ ). However, none of these stimuli elicited a significant response.

Amino acids

With the exception of taurine and threonine, there were no further significant responses in testing single amino acids or the amino acid mixture. Exposure to taurine provoked a significant selection of the control compartment (XIII; $\left.\chi^{2}=5.76, P=0.016, n=100\right)$. Threonine was the only stimulus that was significantly attractive (XIV; $\chi^{2}=7.36$, $P=0.007, n=99)$.

\section{Influence of light conditions}

In one of four experiments that were conducted a second time with artificial light, we found an influence of the ambient light conditions on the behavior of S. entomon. In experiment VI, S. entomon significantly preferred the control $\left(\mathrm{VI}_{\mathrm{a}} ; \chi^{2}=17.69, P=2.6 \times 10^{-5}, n=96\right)$ to the stimulus $\left(\mathrm{VI}_{\mathrm{b}} ; \chi^{2}=2.67, P=0.10, n=95\right)$.

\section{Discussion}

Our findings on Procambarus fallax support data from previous studies that crayfish can effectively discriminate and localize odors with high precision (see Breithaupt 2011). We take this as evidence that in principle the design of our bioassay and the experimental parameters are suitable to study odor tracking in malacostracan crustaceans. In 1800 trials using the same bioassay, Saduria entomon was attracted only to the amino acid threonine and displayed a significantly aversive behavior to taurine, herring and feeding conspecifics. The fact that these animals were not attracted to food-related stimuli is puzzling. Several not mutually exclusive hypotheses might explain these results: (1) Apart from threonine, the range and/or concentrations of stimuli tested did not act as an attractive compound for S. entomon; (2) "long-distance" chemoreception as tested in our bioassay is not ecologically relevant for these animals, and a directed orientation toward food-related odor sources is not part of their foraging strategy; (3) environments that are spatially (and/or temporally) restrictive do not represent an ecologically relevant situation for $S$. entomon and hinder a successful tracking behavior.

\section{Evaluating experimental parameters: water flow, light regime, active compounds and concentrations}

In ecophysiologically relevant experiments, test specimens have to be exposed to stimuli that resemble the conditions in their natural habitat in terms of quality, quantity and 
mode of administration. With regard to flow conditions, velocities below or above a certain threshold will impede or even prevent a successful localization of odor sources (Moore and Grills 1999). The Tvärminne Storfjärd surface water flow velocities have been calculated at $2-4 \mathrm{~cm} \mathrm{~s}^{-1}$ with moderate annual variations (Alenius et al. 1998). Unfortunately, no information on bottom water currents is available, but net flow can be expected to be in the same range. Although S. entomon showed significant responses to four of the applied stimuli, we nevertheless believe that the role of water flow must be explored in more detail in future experiments.

The eyes of S. entomon possess a high sensitivity with maximum absorption close to the wavelength of maximum light transmittance in their habitat (Lindström et al. 1991), which, however, features rather low ambient light conditions (Lindström 2000). Poor light conditions in the habitat, dorsal position of the eyes and relatively small optic neuropils underlying the eyes (Kenning and Harzsch 2013) argue against vision being an important factor in foraging. However, similar to other environmental factors (Pynnönen 1996; Johansson 1999), our results suggest that light may have a distinctive influence on the behavior of $S$. entomon and further attention should be paid to the aspect of lightinduced modulations of behavior.

With respect to the stimulus itself, it has been suggested that certain chemicals represent an inappropriate cue because of little correlation to prey availability. In an omnivorous scavenger such as $S$. entomon, however, such concerns may be less important as it can be assumed that almost any carrion is suitable as food. In contrast, unnaturally high concentrations of a stimulus may have a more profound impact and induce behaviors other than tracking a stimulus source (Weissburg et al. 2002). In other malacostracan crustaceans, homogenates, extracts and soaks of prey were shown to be particularly prone to overdosage, producing unrealistic high stimulus intensities (Weissburg et al. 2002). The responses of mixtures and aqueous prey extracts can be strongly concentration dependent, showing a synergistic suppression effect at higher concentrations (Carr and Derby 1986). Although amino acids were shown to act as an attractive cue at concentrations four orders of magnitude above their background concentration in amphipods (Ide et al. 2006), the response elicited by free amino acids and mixtures is particularly dose dependent (Carr and Derby 1986). These facts offer one possible explanation why most of the amino acid solutions we used in the current study, including the mixture, failed to generate a response. Future tests inevitably have to consider dose-dependent effects.

The two amino acids that did evoke a significant response further complicate the picture. The only attractive odorant in our test (threonine) has not been reported to be a particularly active compound for other foraging crustaceans. In contrast, taurine is well known to initiate food searching and feeding behaviors in Malacostraca (Carr and Derby 1986) and is regarded as one of the predominant amino acids released from injured or freshly dead invertebrates (see Webb and Johannes 1967 and references therein). The finding that $S$. entomon avoids this amino acid raises the question whether concentration dependency due to overstimulation may cause this effect or whether taurine may also be an active compound indicating the presence of, e.g., a predator. Living animals release a wide range of different compounds and metabolites (e.g., Simpson et al. 1959; Zimmer et al. 1999), and it is well known that many species use chemical cues from potential predators (i.e., kairomones) for alarm responses (e.g., Hesselschwerdt et al. 2009).

\section{Evaluating experimental designs: Is directed orientation toward food-related odor sources part of Saduria entomon's foraging strategy?}

Studies on the morphology of the antennae as well as the underlying neuronal network suggest that $S$. entomon is able to perceive, process and use odors (Pynnönen 1985; Kenning and Harzsch 2013). Ablation experiments by Pynnönen (1985) showed that the aesthetasc equipment of antenna 1 is necessary for $S$. entomon to react to chemical stimuli. However, the results presented and discussed above challenge our understanding of foraging strategies of scavenging crustaceans. Green (1957) analyzed the grasping and feeding mechanism of $S$. entomon and provided several observations suggesting that like in terrestrial isopods, (chemo)tactile senses are more important in finding food than olfaction. Reports by Narver (1968) and Pynnönen (1985) also suggest that foraging behavior in $S$. entomon may rather be stimulated by olfactory cues than actually be guided by olfaction. Unpublished observations by the authors using a different bioassay indicate that although baited traps set out in a more spacious environment frequently are crawling with specimens of $S$. entomon, the animal's tracks toward the bait are seemingly random, including large zigzagging loops rather than on a direct course (Kenning et al. in prep). The behavior shown by $S$. entomon thus rather corresponds to kinesis than to actual taxis. The experimental design did not account for this possibility and thus proved to be a suboptimal approach to studying olfactory-guided behaviors in this species. Moreover, it illustrates that established methods to study behavior cannot be readily transferred to other crustacean species.

Acknowledgments We greatly appreciate the support provided by the staff of Tvärminne Zoological Station in collecting the animals 
and for their valuable comments on realizing the project. This study was funded by the Deutsche Forschungsgemeinschaft Ha 2540/9-1.

\section{References}

Alenius P, Myrberg K, Nekrasov A (1998) The physical oceanography of the Gulf of Finland: a review. Boreal Environ Res 3:97-125

Breithaupt $\mathrm{T}$ (2011) Chemical communication in crayfish. In: Breithaupt $\mathrm{T}$, Thiel $\mathrm{M}$ (eds) Chemical communication in crustaceans. Springer, New York, pp 257-276

Carr W, Derby C (1986) Chemically stimulated feeding behavior in marine animals. J Chem Ecol 12:989-1011. doi:10.1007/ BF01638992

Derby CD, Sorensen PW (2008) Neural processing, perception, and behavioral responses to natural chemical stimuli by fish and crustaceans. J Chem Ecol 34:898-914. doi:10.1007/s10886-0089489-0

Ejdung G, Elmgren R (2001) Predation by the benthic isopod Saduria entomon on two Baltic Sea deposit-feeders, the amphipod Monoporeia affinis and the bivalve Macoma balthica. J Exp Mar Biol Ecol 266:165-179

Green J (1957) The feeding mechanism of Mesidotea entomon (Linn.) (Crustacea: Isopoda). Proc Zool Soc Lond 129:245-254

Hallberg E, Skog M (2011) Chemosensory sensilla in crustaceans. In: Breithaupt $\mathrm{T}$, Thiel $\mathrm{M}$ (eds) Chemical communication in crustaceans. Springer, New York, pp 103-121

Hazlett BA (2011) Chemical cues and reducing the risk of predation. In: Breithaupt $\mathrm{T}$, Thiel $\mathrm{M}$ (eds) Chemical communication in crustaceans. Springer, New York, pp 355-370

Hesselschwerdt J, Tscharner S, Necker J, Wantzen KM (2009) A local gammarid uses kairomones to avoid predation by the invasive crustaceans Dikerogammarus villosus and Orconectes limosus. Biol Invasions 11:2133-2140. doi:10.1007/s10530-0099492-6

Horner AJ (2004) Dual antennular chemosensory pathways can mediate orientation by Caribbean spiny lobsters in naturalistic flow conditions. J Exp Biol 207:3785-3796. doi:10.1242/jeb. 01200

Ide K, Takahashi K, Nakano T et al (2006) Chemoreceptive foraging in a shallow-water scavenging lysianassid amphipod: role of amino acids in the location of carrion in Scopelocheirus onagawae. Mar Ecol Prog Ser 317:193

Johansson B (1999) Influence of oxygen levels on the predatory behaviour of the isopod Saduria entomon. Mar Freshw Behav Physiol 32:223-238

Kats LB, Dill LM (1998) The scent of death: chemosensory assessment of predation risk by prey animals. Ecoscience 5:361-394

Kenning M, Harzsch S (2013) Brain anatomy of the marine isopod Saduria entomon Linnaeus, 1758 (Valvifera, Isopoda) with special emphasis on the olfactory pathway. Front Neuroanat. doi:10.3389/fnana.2013.00032

Krång A-S, Baden SP (2004) The ability of the amphipod Corophium volutator (Pallas) to follow chemical signals from con-specifics. J Exp Mar Biol Ecol 310:195-206. doi:10.1016/j.jembe.2004.04. 010

Leonardsson K (1991) Effect of cannibalism and alternative prey on population dynamics of Saduria entomon (Isopoda). Ecology $72: 1273-1285$

Lindström M (2000) Seasonal changes in the underwater light milieu in a Finnish Baltic Sea coastal locality. Geophysica 36:215-232

Lindström M, Fortelius W, Meyer-Rochow VB (1991) Exposure to bright light has little effect on eye sensitivity and ultrastructure of Saduria entomon (Crustacea; Isopoda; Valvifera). Zool Sci 8:653-663

Martin P, Dorn NJ, Kawai T et al (2010) The enigmatic Marmorkrebs (marbled crayfish) is the parthenogenetic form of Procambarus fallax (Hagen, 1870). Contrib Zool 79:107-118

Moore PA, Grills JL (1999) Chemical orientation to food by the crayfish Orconectes rusticus: influence of hydrodynamics. Anim Behav 58:953-963

Mopper K, Dawson R (1986) Determination of amino acids in sea water: recent chromatographic developments and future directions. Sci Total Environ 49:115-131

Narver DW (1968) The Isopod Mesidotea entomon in the Chignik Lakes, Alaska. J Fish Board Can 25:157-167

Nikitina S, Spasskii N (1963) Some observations on the biology of the marine isopod Mesidotea entomon and the mysids Mysis mixta, Mysis oculata var. relicta and Neomysis vulgaris in the southern Baltic Sea. Atlant Nauchno-Issl Inst Rybn Khozyaistva Okeanogr AtlantNIRO 10:64-78

Premke K, Muyakshin S, Klages M, Wegner J (2003) Evidence for long-range chemoreceptive tracking of food odour in deep-sea scavengers by scanning sonar data. J Exp Mar Biol Ecol 285:283-294

Pynnönen K (1985) The structure of long distance (antennular) chemoreceptors in Saduria entomon (L.), Isopoda, and their role in feeding behaviour. Ann Zool Fenn 22:423-432

Pynnönen K (1996) Heavy metal-induced changes in the feeding and burrowing behaviour of a Baltic isopod, Saduria (Mesidotea) entomon L. Mar Environ Res 41:145-156

Schneider RAZ, Schneider RW, Moore PA (1999) Recognition of dominance status by chemoreception in the red swamp crayfish, Procambarus clarkii. J Chem Ecol 25:781-794

Seitz R, Vilpoux K, Hopp U et al (2005) Ontogeny of the Marmorkrebs (marbled crayfish): a parthenogenetic crayfish with unknown origin and phylogenetic position. J Exp Zool A Comp Exp Biol 303:393-405

Simpson JW, Allen K, Awapara J (1959) Free amino acids in some aquatic invertebrates. Biol Bull 117:371-381

Team RDC et al. (2005) R: a language and environment for statistical computing. ISBN 3-900051-07-0. R Foundation for Statistical Computing. Vienna, Austria, 2013. http://www.R-project.org

Thiel M (2011) Chemical communication in peracarid crustaceans. In: Breithaupt $\mathrm{T}$, Thiel $\mathrm{M}$ (eds) Chemical communication in crustaceans. Springer, New York, pp 199-218

Tiselius P, Saiz E, Kiørboe T (2013) Sensory capabilities and food capture of two small copepods, Paracalanus parvus and Pseudocalanus sp. Limnol Oceanogr 58:1657-1666

Webb KL, Johannes R (1967) Studies of the release of dissolved free amino acids by marine zooplankton. Limnol Oceanogr $12: 376-382$

Weissburg MJ (2011) Waterborne chemical communication: stimulus dispersal dynamics and orientation strategies in crustaceans. In: Breithaupt $\mathrm{T}$, Thiel $\mathrm{M}$ (eds) Chemical communication in crustaceans. Springer, New York, pp 63-83

Weissburg MJ, Zimmer-Faust RK (1994) Odor plumes and how blue crabs use them in finding prey. J Exp Biol 197:349-375

Weissburg MJ, Ferner MC, Pisut DP, Smee DL (2002) Ecological consequences of chemically mediated prey perception. J Chem Ecol 28:1953-1970

Wyatt TD (2011) Pheromones and behavior. In: Breithaupt T, Thiel $\mathrm{M}$ (eds) Chemical communication in crustaceans. Springer, New York, pp 23-38

Zimmer RK, Commins JE, Browne KA (1999) Regulatory effects of environmental chemical signals on search behavior and foraging success. Ecology 80:1432-1446 